\title{
Contiguous Multilevel Vertebral Osteomyelitis without Adjacent Intervertebral Discs Involvement
}

Sir,

Vertebral osteomyelitis is often insidious and its nonspecific symptoms make diagnosis difficult. We would like to report a case of an atypical vertebral bacterial osteomyelitis, in which the magnetic resonance imaging (MRI) examination demonstrated intact vertebral end plates and disc spaces, although the adjacent vertebral bodies were extensively involved. 


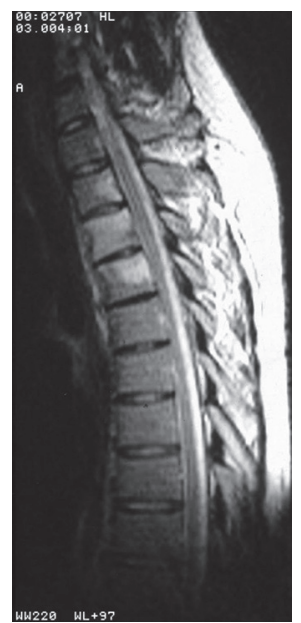

Figure 1: Sagittal T2-weighted image reveals the involvement of the whole T3 vertebral body and the adjacent halves of the T2 and T4 vertebrae with intervertebral discs and end plates sparing

A 27-year-old male presented to the emergency department with a 3-week history of right T3-T4 intercostal neuralgia. He had neither previous medical history nor previous trauma, or infection was reported. Twelve days before the onset of his symptom, the patient had undergone a dental procedure. He was in a good physical state and afebrile. Neurological examination was normal. There was a constant, moderate upper right thoracic paraspinal tenderness exacerbated by movement. The remainder of the physical examination findings was unremarkable. Initial laboratory tests revealed an elevated erythrocyte sedimentation rate and C-reactive protein level.

MRI of the thoracic spine revealed decreased signal intensity lesions on T1-weighted images and high signal lesions on T2-weighted images involving the whole $\mathrm{T} 3$ vertebral body and the adjacent halves of the $\mathrm{T} 2$ and T4 vertebrae [Figure 1], as well as a middle's vertebral column soft-tissue mass extending to the right $\mathrm{T} 3-\mathrm{T} 4$ intervertebral foramen compromising the ipsilateral nerve root. These lesions were enhanced after gadolinium administration. However, the adjacent disc spaces were spared and no abnormal signal was identified. All vertebrae end plates were also normal without the typical signs of erosion or destruction. To determine a certain diagnosis, the patient was submitted to a computed tomography scan-guided percutaneous needle biopsy of the soft-tissue mass, and bacteriological studies were positive for Staphylococcus aureus. The patient was treated with teicoplanin and rifampicin and had an uneventful course. Twelve weeks after treatment completed, MRI images revealed the infection markedly decreased [Figure 2]; there was no late recurrence.

In this otherwise healthy young adult patient, without predisposing factors or notable social risks, dental

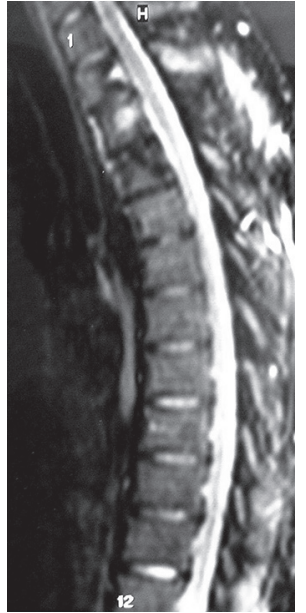

Figure 2: Sagittal T2-weighted image 12 weeks after treatment completed revealed the vertebrae infection markedly decreased

procedure as a portal of bacteria entry was considered the most likely etiology resulting in the hematogenous spread of pathogen organism. Diagnosis of spinal infections is based on clinical and radiological features and often is delayed or missed due to the rarity of the disease and the insidious onset of symptoms. ${ }^{[1]}$ Atypical manifestations of proven spinal infections with isolated spondylitis without the involvement of adjacent disks have been previously described as a rare finding and are thought to represent an early manifestation of spinal infection. ${ }^{[2-5]}$ Thus, we emphasize on the fact that a clinician should know and consider these atypical findings so as not to exclude infection and distinguish this disease from other destructive lesions of the spine when some of the typical radiological signs are lacking.

\section{Financial support and sponsorship}

Nil.

\section{Conflicts of interest}

There are no conflicts of interest.

\section{Aristedis Rovlias, Dimitrios Bougiouklis}

Department of Neurosurgery, Asclepeion General Hospital of Voula, Athens, Greece

Address for correspondence: Dr. Aristedis Rovlias, Department of Neurosurgery, Asclepeion General Hospital of Athens, 1 Vasileos Pavlou Street, 16 673, Voula, Athens, Greece. E-mail: arovlias@yahoo.com

\section{REFERENCES}

1. Higgins LS, Tarmey TT, Szostek JH. 53-year-old man with fever and back pain. Mayo Clin Proc 2016;91:e75-9.

2. Hadjipavlou AG, Mader JT, Necessary JT, Muffoletto AJ. Hematogenous pyogenic spinal infections and their surgical management. Spine (Phila Pa 1976) 2000;25:1668-79.

3. Ledermann HP, Schweitzer ME, Morrison WB, Carrino JA. MR imaging findings in spinal infections: Rules or myths? Radiology 2003;228:506-14. 
4. Chen TY, Wu TC, Tsui YK, Chen HH, Lin CJ, Lee HJ, et al. Diffusion-weighted magnetic resonance imaging and apparent diffusion coefficient mapping for diagnosing infectious spondylodiscitis: A preliminary study. J Neuroimaging 2015;25:482-7.

5. Berbari EF, Kanj SS, Kowalski TJ, Darouiche RO, Widmer AF, Schmitt SK, et al. 2015 Infectious Diseases Society of America (IDSA) clinical practice guidelines for the diagnosis and treatment of native vertebral osteomyelitis in adults. Clin Infect Dis 2015;61:e26-46.

This is an open access journal, and articles are distributed under the terms of the Creative Commons Attribution-NonCommercial-ShareAlike 4.0 License, which allows others to remix, tweak, and build upon the work non-commercially, as long as appropriate credit is given and the new creations are licensed under the identical terms.

\begin{tabular}{|l|l|}
\hline \multicolumn{2}{|c|}{ Access this article online } \\
\hline Quick Response Code: & Website: \\
\hline
\end{tabular}

How to cite this article: Rovlias A, Bougiouklis D. Contiguous multilevel vertebral osteomyelitis without adjacent intervertebral discs involvement. J Neurosci Rural Pract 2018;9:443-5. 